\title{
Should critically ill patients with COVID-19 be managed in high-volume ICUs?
}

Mahesh Ramanan, Aidan Burrell and Andrew Udy, for the SPRINT-SARI Australia Investigators.

www.doi.org/10.51893/2020.4.11

Published online first 7 December 2020

To the Editor: The coronavirus disease 2019 (COVID-19) pandemic has resulted in 38394169 cases and 1089047 deaths worldwide as of 15 October 2020, although to date, Australia has been relatively spared, with only 11441 cases and 118 deaths. ${ }^{1}$ Globally, health care systems and intensive care units (ICUs) have been under immense pressure and wide regional variation in mortality has been observed, both between ${ }^{2-5}$ and within countries. ${ }^{6}$ It has been suggested that a higher ICU case volume of COVID-19 may be associated with increased mortality, although this has not yet been systematically investigated. Intuitively, a negative volumeoutcome association is plausible under pandemic conditions, as a stretched system running above maximal capacity may not be able to deliver its usual standard of care.
The SPRINT-SARI (Short Period Incidence Study of Severe Acute Respiratory Infection) Australia study aims to provide near real-time observational data on patients with COVID-19 admitted to participating ICUs. Herein, we report results of an interim analysis of the SPRINT-SARI database to determine whether a COVID-19 case volume-outcome association exists locally at participating sites.

Data pertaining to confirmed COVID-19 ICU admissions in the SPRINT-SARI database between 27 February and 30 June 2020 were extracted. The primary exposure variable was case volume. Sites were dichotomised into a lowvolume group (LVG) and high-volume group (HVG) based on the median number of COVID-19 admissions to each institution. The primary outcome was hospital mortality.
Table 1. Patient characteristics and outcomes for confirmed coronavirus disease 2019 (COVID-19) intensive care unit (ICU) admissions

\begin{tabular}{|c|c|c|}
\hline & Low-volume group & High-volume group \\
\hline Total number of patients & 102 & 130 \\
\hline \multicolumn{3}{|l|}{ Demographic characteristics } \\
\hline Age (years), median (IQR) & $68(57-72)$ & $62(49-72)$ \\
\hline Sex, female & $32(31 \%)$ & $42(33 \%)$ \\
\hline Body mass index $\left(\mathrm{kg} / \mathrm{m}^{2}\right)$, median (IQR) & $30(25-32)$ & $29(24-32)$ \\
\hline Smoking history & $18(18 \%)$ & $17(13 \%)$ \\
\hline \multicolumn{3}{|l|}{ Comorbidities } \\
\hline Obesity & $23(23 \%)$ & $32(25 \%)$ \\
\hline Diabetes & $26(25 \%)$ & $38(29 \%)$ \\
\hline Asthma & $12(12 \%)$ & $12(9 \%)$ \\
\hline $\mathrm{ACEl} / \mathrm{A} 2 \mathrm{RB}$ & $23(23 \%)$ & $27(21 \%)$ \\
\hline Chronic cardiovascular disease & $24(24 \%)$ & $17(13 \%)$ \\
\hline Day 1 APACHE II score, median (IQR) & $16(12-19)$ & $13(8-17)$ \\
\hline \multicolumn{3}{|l|}{ Outcomes } \\
\hline Mortality & $17(17 \%)$ & $14(11 \%)$ \\
\hline Still in ICU & $14(14 \%)$ & $22(17 \%)$ \\
\hline
\end{tabular}

Patients still in hospital were excluded from the mortality analysis. Mixed effects logistic regression was performed using age, Acute Physiological and Chronic Health Evaluation (APACHE) II score, and receipt of mechanical ventilation as fixed effects and site as a random effect, with patients nested within sites. Odds ratio (OR) of death with $95 \%$ confidence interval $(\mathrm{Cl})$ and $P$ values are reported.

We performed sensitivity analyses, defining low and high case volume on the basis of the median ICUbed hours and an arbitrary cut-off of ten or more confirmed COVID-19 cases, and modelling volume as a continuous variable 


\section{LETTER}

Table 2. Adjusted hospital mortality and sensitivity analyses for confirmed coronavirus disease 2019 (COVID-19) admissions with completed outcome

\begin{tabular}{|c|c|c|c|c|}
\hline & $\begin{array}{l}\text { Low-volume } \\
\text { group }\end{array}$ & $\begin{array}{l}\text { High-volume } \\
\text { group }\end{array}$ & $\begin{array}{c}\text { Adjusted OR } \\
(95 \% \mathrm{Cl})\end{array}$ & $P$ \\
\hline \multicolumn{5}{|l|}{ Primary outcome* } \\
\hline Median split by site volume & $17 / 102(17 \%)$ & $14 / 130(11 \%)$ & $\begin{array}{c}0.96 \\
(0.35-2.63)\end{array}$ & 0.93 \\
\hline \multicolumn{5}{|l|}{ Sensitivity analyses* } \\
\hline Median split by ICU-bed hours & $20 / 128(16 \%)$ & $11 / 104(11 \%)$ & $0.9(0.32-2.54)$ & 0.85 \\
\hline High-volume arbitrarily set to $>10$ COVID-19 admissions & $22 / 134(16 \%)$ & $9 / 98(9 \%)$ & $\begin{array}{c}1.41 \\
(0.47-4.27)\end{array}$ & 0.54 \\
\hline Site volume as a continuous variable & na & na & $1.04(0.98-1.1)$ & 0.17 \\
\hline Site ICU-bed hours as a continuous variable (per 100 hours) & na & na & $\begin{array}{c}1.02 \\
(0.99-1.04)\end{array}$ & 0.27 \\
\hline \multicolumn{5}{|l|}{ With sample limited to mechanical ventilation patients only ${ }^{\dagger}$} \\
\hline Median split by site volume & $14 / 62(23 \%)$ & $12 / 68(18 \%)$ & $\begin{array}{c}0.91 \\
(0.29-2.82)\end{array}$ & 0.87 \\
\hline Median split by ICU-bed hours & $17 / 79(22 \%)$ & $9 / 51(18 \%)$ & $\begin{array}{c}0.81 \\
(0.25-2.62)\end{array}$ & 0.73 \\
\hline High-volume arbitrarily set to $>10$ COVID-19 admissions & $19 / 90(21 \%)$ & $7 / 40(18 \%)$ & $1.3(0.36-4.69)$ & 0.69 \\
\hline Site volume as a continuous variable & na & na & $\begin{array}{c}1.04 \\
(0.95-1.13)\end{array}$ & 0.43 \\
\hline Site ICU-bed hours as a continuous variable (per 100 hours) & na & na & $\begin{array}{c}1.01 \\
(0.97-1.05)\end{array}$ & 0.6 \\
\hline
\end{tabular}

ICU =intensive care unit; $\mathrm{na}=$ not applicable; OR $=$ odds ratio. ${ }^{*} n=196 .+n=130$.

(separate models for number of cases and ICU-bed hours as the marker of volume). Moreover, all analyses were repeated with only patients who received mechanical ventilation.

There were 232 confirmed COVID-19 admissions in 47 ICUs, and of these, 196 (84\%) were discharged from hospital. There were $102(44 \%)$ admissions in the LVG (median site volume, 4; interquartile range $[\mathrm{IQR}], 2-5$ ) and $130(56 \%)$ in the HVG (median, 12; IQR, 10-37). Demographic characteristics and outcomes are described in Table 1 . The mechanical ventilation rate was $61 \%$ in the LVG and $52 \%$ in the HVG. Crude mortality was $17 / 102$ $(17 \%)$ and $14 / 130(11 \%)$ in the LVG and HVG respectively. After adjustment for age, APACHE II score and mechanical ventilation, there was no statistically significant difference in mortality in the HVG compared with LVG (OR, 0.96; $95 \%$ $\mathrm{Cl}, 0.35-2.63 ; P=0.93)$.

All the sensitivity analyses (Table 2 ) also demonstrated that there were no significant differences in mortality based on case volume, regardless of whether all patients or only mechanically ventilated patients were analysed.

While the SPRINT-SARI database offers comprehensive data on critically ill patients with COVID-19 in Australia, there are some important limitations to acknowledge. The overall case numbers were small, limiting the number of covariates that could reasonably be adjusted for. The number of confirmed COVID-19 admissions at each individual site was very small. We also did not have data pertaining to overall ICU capacity at individual sites.

There are currently insufficient data to determine whether there is a case volume-outcome association for COVID-19 mortality in Australian ICUs. As the COVID-19 pandemic is still unfolding, such relationships may emerge, highlighting the necessity of ongoing monitoring via platforms such as SPRINT-SARI.

\section{Acknowledgements}

SPRINT-SARI Australia Management Committee: Aidan Burrell, Allen Cheng, Andrew Udy, Annamaria Palermo, Benjamin Reddi, Claire Reynolds, Craig French, D James Cooper, Edward Litton, Husna Begum, Lewis Campbell, Mahesh Ramanan, Mark Plummer, Richard McAllister, Simon Erickson, Tessa Broadley, Tony Trapani and Winston Cheung.

SPRINT-SARI Australia Investigators: Adam Visser, Adrian Mattke, Adrian Regli, Alan Rashid, Alexis Tabah, Alison Walker, Allen Cheng, Amanda Corley, Andrew Udy, Anil Ramnani, Anthony Eidan, Bart DeKeulenaer, Benjamin Reddi, Brent Richards, Cameron Knott, Cara Moore, Carmel Delzoppo, Catherine Boschert, Catherine Tacon, Craig French, Danielle Austin, David Brewster, David Cooper, David Crosbie, David Hawkins, Edda 


\section{LETTER}

Jessen, Eduardo Martinez, Edward Fysh, Edward Litton, Felix Oberender, Forbes McGain, Gavin Salt, Glenn Eastwood, Gopal Taori, Hayden White, Hergen Buscher, Ian Seppelt, Isabel Anne Leditschke, Janelle Young, Jayshree Lavana, Jeremy Cohen, Jessica Lugsdin, John Botha, John Santamaria, Jonathan Barrett, Kasha Singh, Kevin Laupland, Khaled El-Khawas, Kristine Estensen, Kush Deshpande, Kyle White, Leigh Fitzpatrick, Lewis Campbell, Mahesh Ramanan, Manoj Saxena, Marion Kainer, Mark Kol, Mark Page, Mark Plummer, Martin Sterba, Matthew Anstey, Matthew Brain, Matthew Maiden, Myrene Kilminster, Naomi Hammond, Neeraj Bhadange, Nicole Humphreys, Paras Jain, Paul Azzi, Paul Secombe, Paula Lister, Peter Chan, Peter McCanny, Phillip Britton, Pierre Janin, Ravi Krishnamurthy, Ravikiran Sonawane, Ravindranath Tiruvoipati, Richard Totaro, Rinaldo Bellomo, Ritesh Sanghavi, Samantha Bates, Sandra Peake, Shailesh Bihari, Shane George, Simon Erickson, Steve Webb, Subhash Arora, Subodh Ganu, Thomas Rozen, Toni McKenna, Umesh Kadam, Vineet Nayyar, Wei Han Choy and Wisam Albassam.

SPRINT-SARI Australia participating sites: Albury Wodonga Health, Alice Springs Hospital, Angliss Hospital, Austin Hospital, Ballarat Base Hospital, Bankstown-Lidcombe Hospital, Barwon Health, Bendigo Hospital, Box Hill Hospital, Bunbury Hospital, Bundaberg Hospital, Caboolture Hospital, Cabrini Hospital Malvern, Cairns Hospital, Calvary Mater Newcastle, Campbelltown Hospital, Canberra Hospital, Concord Hospital, Dandenong Hospital, Epworth Richmond, Fiona Stanley Hospital, Flinders Medical Centre, Footscray Hospital, Frankston Hospital, Gold Coast University Hospital, Hervey Bay Hospital, Ipswich Hospital, John Hunter Hospital, Joondalup Health Campus, Launceston General Hospital, Lismore Base Hospital, Liverpool Hospital, Logan Hospital, Lyell McEwan Hospital, Maroondah Hospital, Mater Hospital Brisbane, Mildura Base Hospital, Monash Children's Hospital, Monash Medical Centre, Nepean Hospital, Northeast Health Wangaratta, Northern Hospital, Perth Children's Hospital, Port Macquarie Base Hospital, Prince of Wales Hospital, Princess Alexandra Hospital, Queensland Children's Hospital, Redcliffe Hospital, Rockingham Hospital, Royal Adelaide Hospital, Royal Brisbane and Women's Hospital, Royal Children's Hospital, Royal Darwin Hospital, Royal Hobart Hospital, Royal Melbourne Hospital, Royal North Shore Hospital, Royal Perth Hospital, Royal Prince Alfred Hospital, Sir Charles Gairdner Hospital, St George Hospital, St John of God Hospital Midland, St John of God Hospital Murdoch, St Vincent's Hospital Melbourne, St. Vincent's Hospital Sydney, Sunshine Coast University Hospital, Sunshine Hospital, Sydney Children's Hospital Randwick, The Alfred Hospital, The Children's Hospital at Westmead, The Prince Charles Hospital, The Queen Elizabeth Hospital, Toowoomba Hospital, Warrnambool Base Hospital, Werribee Mercy Hospital, Westmead Hospital, Wollongong Hospital and Women's and Children's Hospital Adelaide.

\section{Competing interests}

None declared.

\section{Author details}

Mahesh Ramanan 1,2,3

Aidan Burrell ${ }^{4,5}$

Andrew Udy 4,5

For the SPRINT-SARI Australia Investigators.

1 Intensive Care Units, Caboolture Hospital and The Prince Charles Hospital, Metro North Hospitals and Health Services, Brisbane, QLD, Australia.

2 Critical Care Division, The George Institute for Global Health, University of New South Wales, Sydney, NSW, Australia.

3 School of Medicine, University of Queensland, Brisbane, QLD, Australia.

4 Department of Intensive Care and Hyperbaric Medicine, The Alfred Hospital, Melbourne, VIC, Australia.

5 Australian and New Zealand Intensive Care Research Centre, Monash University, Melbourne, VIC.

Correspondence: Mahesh.Ramanan@health.qld.gov.au

\section{References}

1 World Health Organization. Coronavirus disease (COVID-19) dashboard. https://covid19.who.int (viewed 15 Oct 2020)

2 Bhatraju PK, Ghassemieh BJ, Nichols M, et al. COVID-19 in critically ill patients in the Seattle Region - case series. N Eng J Med 2020; 382: 2012-22.

3 Grasselli G, Zangrillo A, Zanella A, et al. Baseline characteristics and outcomes of 1591 patients infected with SARS-CoV-2 Admitted to ICUs of the Lombardy Region, Italy. JAMA 2020; 323: 1574-81

4 Yang $X, Y u Y, X u$ J, et al. Clinical course and outcomes of critically ill patients with SARS-CoV-2 pneumonia in Wuhan, China: a single-center, retrospective, observational study. Lancet Respir Med 2020; 8: 475-81.

5 Docherty AB, Harrison EM, Green CA, et al. Features of 20133 UK patients in hospital with COVID-19 using the ISARIC WHO Clinical Characterisation Protocol: Prospective observational cohort study. BMJ 2020; 369: 1-12.

6 Qian Z, Alaa AM, van der Schaar M, et al. Between-centre differences for COVID-19 ICU mortality from early data in England. Intensive Care Med 2020; 46: 1779-80. 